\title{
In vitro demonstration of salinomycin as a novel chemotherapeutic agent for the treatment of SOX2-positive glioblastoma cancer stem cells
}

\author{
JUSTIN W. MAGRATH ${ }^{1}$, WILSON R. RANEY and YONGHYUN KIM \\ Department of Chemical and Biological Engineering, The University of Alabama, \\ Tuscaloosa, AL 35487-0203, USA
}

Received October 29, 2019; Accepted May 19, 2020

DOI: $10.3892 / o r .2020 .7642$

\begin{abstract}
Glioblastoma multiforme (GBM) is the deadliest and most common form of primary brain tumor. Conventional treatments are ineffective at treating GBM due to the heterogeneous cellular makeup of the tumors as well as the existence of drug-resistant cells known as cancer stem cells (CSCs). CSCs have the ability to initiate tumorigenesis and self-renew, which can lead to recurrence. Salinomycin, an antibiotic commonly used in agricultural feed, has been revealed to target CSCs in other cancer types. A few studies have suggested salinomycin can be effective at treating glioblastoma stem cells (GSCs); however, no study has examined the effect of salinomycin treatment on GSC markers. In the present study, flow cytometry, RT-qPCR, and limiting dilution assays were used to further analyze the effects of salinomycin on GSCs. It was revealed that salinomycin decreased the expression of the GSC marker SOX2 at both the transcriptional and translational level. However, the effect of salinomycin on the GSC markers Nestin and CD133 was inconsistent between GBM subtypes. Additionally, the present findings provide initial evidence of caspase-3-dependent and independent apoptosis as the method by which salinomycin induces cell death in GBM. The present results indicated that salinomycin is an effective candidate as a chemotherapeutic agent that can treat GBM by targeting both bulk tumor cells as well as CSCs.
\end{abstract}

Correspondence to: Professor Yonghyun Kim, Department of Chemical and Biological Engineering, The University of Alabama, P.O. Box 870203, Tuscaloosa, AL 35487-0203, USA

E-mail: ykim@eng.ua.edu

Present address: ${ }^{1}$ Center for Stem Cell Research and Regenerative Medicine, Tulane University School of Medicine, New Orleans, LA 70112, USA

Key words: salinomycin, glioblastoma, cancer stem cell, apoptosis, chemotherapy

\section{Introduction}

Glioblastoma multiforme (GBM) is the most common and deadliest form of brain cancer (1-3). Although current treatments are rigorous, including surgery and chemotherapy, the prognosis for patients with GBM remains poor. The median survival rate is 14.6 months, and the two-year survival rate is $30 \%(1,4)$. This poor prognosis in GBM and other solid tumors is often attributed to the presence of cancer stem cells (CSCs) (5-8). This subpopulation of cells has the unique abilities to self-renew, differentiate, and initiate tumorigenesis. Due to this, CSCs play an important role in recurrence and metastasis. Glioblastoma stem cells (GSCs) have also been revealed to be resistant to conventional therapies $(9,10)$, underscoring the need to develop treatments that account for the cellular heterogeneity found in GBM environments, specifically with regard to GSCs.

While the properties of self-renewal, differentiation, and tumorigenesis define GSCs, practically, it is easier to use GSC markers for their identification. These markers are proteins that are commonly expressed by GSCs and associated with the stem cell phenotype (11). A variety of GSC markers have been proposed and debate continues on which markers are the most accurate (11). Three of the most commonly examined GSC markers are CD133, SOX2 [SRY (sex determining region Y)box transcription factor 2], and Nestin. CD133 is a cell surface glycoprotein of unknown function and was the first identified GSC marker $(6,8,11)$. Cells that are $C D 133$-positive have exhibited an increased ability to form tumors in vivo. SOX2 is a marker of embryonic stem cells used in somatic reprogramming. The knockdown of SOX2 in GSCs has been revealed to reduce their tumorigenesis and chemoresistance (12). Nestin is a class VI intermediate filament also found in non-malignant neural stem cells. Nestin-positive cells have demonstrated radioresistance and increased tumor formation (13).

One drug that has shown promise in targeting CSCs is salinomycin, a monocarboxylic polyether antibiotic isolated from Streptomyces albus (14). Salinomycin has been used as an anticoccidial in poultry since the 1970 s, and it acts as an ionophore with a preference for $\mathrm{Na}^{+}$and $\mathrm{K}^{+}(15)$. A high-throughput study in 2009 identified the potential of salinomycin to kill stem cell-like breast cancer cells and significantly reduce 
their tumor seeding ability in mice (14). Several other studies since then have revealed the effect of this drug on other types of CSCs including acute myeloid leukemia, lung cancer, colorectal cancer, and prostate cancer (16-18). Salinomycin has been revealed to overcome ATP-binding cassette transporters in acute myeloid leukemia, inhibit the Wnt signaling in chronic lymphocytic leukemia, and induce apoptosis in both of these cancers (19-21). The mechanism by which salinomycin exerts these capabilities remains unknown.

In a previous study, we hypothesized that salinomycin would specifically target the GSCs (22). Although several studies have suggested that salinomycin is effective against GBM, the effect of the drug on GSCs is understudied. Prior studies demonstrated that salinomycin decreases the viability of GSC-enriched cultures more than non-GSC enriched cultures, and that salinomycin inhibits neurosphere formation, a functional marker for stemness (23-25). In the present study, we corroborated these previous studies on the susceptibility of GSC-enriched cultures and neurosphere formation. Furthermore, novel evidence was provided of the ability of salinomycin to decrease the expression of the GSC marker SOX 2 at both the transcriptional and translational level. Finally, preliminary evidence was provided that salinomycin-induced death of GSCs is achieved via the apoptotic pathway.

\section{Materials and methods}

Cell culture. Three human glioblastoma cell lines were used: Established glioblastoma cell line of unknown origin U87-MG (ATCC HTB-14) (26), primary glioblastoma cell line SMC448 (kindly provided and STR-profiled by Dr Do-Hyun Nam, Samsung Medical Center) (27), and proneural patient-derived xenograft GBM line D456 (kindly provided and STR-profiled by Dr G. Yancey Gillespie, Department of Neurosurgery, University of Alabama at Birmingham) (28). A mouse neural stem cell line NE-4C (ATCC CRL-2925) was also used. The cells were grown in either serum-containing or serum-free culture media. Serum-free culture cells were grown in neurobasal-A media supplemented with $1 \mathrm{mM}$ glutamine (Life Technologies; Thermo Fisher Scientific, Inc.), $8 \mu \mathrm{g} / \mathrm{ml}$ heparin (J.T. Baker Chemical Co.), 0.5X N-2 and 0.5X B-27 (both from Gibco; Thermo Fisher Scientific, Inc.), $1 \%$ penicillin/streptomycin (Corning, Inc.), $20 \mathrm{ng} / \mathrm{ml}$ epidermal growth factor and $10 \mathrm{ng} / \mathrm{ml}$ fibroblast growth factor (both from Shenandoah Biotechnology, Inc.) (NBE media). Serum culture cells were grown in Eagle's minimal essential medium supplemented with $10 \%$ fetal bovine serum and $1 \%$ penicillin/streptomycin (Corning, Inc.) (EMEM media).

Light microscopy. VistaVision Microscope (VWR \#82026-630) at $x 4$ magnification was used to observe the morphology of cells in serum and serum-free culture. The microscope at a magnification of $\mathrm{x} 10$ was also used to observe sphere formation ability.

Salinomycin treatment. For all experiments, the same salinomycin treatment procedure was followed. Cells were seeded in appropriate media (NBE for serum-free culture, EMEM for serum culture) and incubated for $24 \mathrm{~h}$ at $37^{\circ} \mathrm{C}$. After $24 \mathrm{~h}$, salinomycin (MP Biomedicals, LLC) reconstituted in dimethyl sulphoxide (DMSO) or mock control (DMSO alone) was added to a final concentration of $0.1 \% \mathrm{v} / \mathrm{v}$ DMSO. Cells were incubated for an additional $48 \mathrm{~h}$ at $37^{\circ} \mathrm{C}$ and then collected for analysis.

Viability assay. For the viability assay, $1 \times 10^{4}$ cells in $100 \mu \mathrm{l}$ of media per well were seeded in 96-well plates. Cell Counting Kit-8 (CCK-8), a water-soluble tetrazolium salt-based colorimetric assay, was used to determine the cell viability as per the manufacturer's protocol (Sigma Aldrich-Merck KGaA). Briefly, $10 \mu \mathrm{l}$ of CCK-8 solution per well was added to salinomycin-treated and mock-treated cells, incubated in a humidified incubator at $37^{\circ} \mathrm{C}$ for $4 \mathrm{~h}$, and the absorbance was measured at $\lambda=450 \mathrm{~nm}$.

Flow cytometry. For flow cytometry, $3 \times 10^{5}$ cells in $3 \mathrm{ml}$ of media per well were seeded in 6-well plates. Flow cytometry was used to assess the expression of SOX2. NE-4C, U87-MG, D456, and SMC448 were cultured in NBE (serum-free culture) or EMEM (serum culture) for $48 \mathrm{~h}$ with $1 \mu \mathrm{M}$ salinomycin or mock control (DMSO). Cells were then pelleted, resuspended in $4 \%$ paraformaldehyde, then in a permeabilization buffer (BD Cytofix/Cytoperm ${ }^{\mathrm{TM}}$; cat. no. 554722; BD Biosciences) on ice for $15 \mathrm{~min}$, and stained with Alexa Fluor 647 anti-SOX2 antibody (cat. no. 562139; dilution 1:10 dilution; BD Biosciences) on ice for $30 \mathrm{~min}$. Flow cytometry was then performed analyzing 20,000 events per sample using BD Accuri C6 flow cytometer (BD Biosciences). Results were analyzed using Accuri C6 software (v1.0; BD Biosciences).

Flow cytometry was also used to assess apoptosis. U87-MG, D456, and SMC448 were cultured in NBE (serum-free culture) or EMEM (serum culture) for $48 \mathrm{~h}$ with $1 \mu \mathrm{M}$ salinomycin or mock control. Cells were then pelleted, dissolved in Annexin V binding buffer, and double-stained with Annexin V (Enzo Life Sciences) and 7-AAD (EMD Millipore). Flow cytometry was performed analyzing 20,000 events per sample using BD Accuri C6 flow cytometer. Specific apoptosis was calculated as established previously using the following equation: (Late apoptotic population with $1 \mu \mathrm{M}$ Sal-late apoptotic population with $0 \mu \mathrm{M} \mathrm{Sal}) /(100$-late apoptotic population with $0 \mu \mathrm{M} \mathrm{Sal}) \mathrm{x} 100$.

Finally, flow cytometry was used to assess caspase-3 cleavage. Caspase-3 cleavage was determined using NucView ${ }^{\circledR} 488$ Caspase- 3 assay kit (Biotium; cat. no. 30029). The assay was conducted according to manufacturer's protocol. Flow cytometry was performed analyzing 20,000 events per sample using BD Accuri C6 flow cytometer.

Real-time quantitative PCR (RT-qPCR). For RT-qPCR, $3 \times 10^{5}$ cells in $3 \mathrm{ml}$ of media per well were seeded in 6 -well plates. Primers were designed by retrieving nucleotide sequences from the NCBI gene database for SOX2 (NM_003106), Nestin (NM_006617), Prominin1/CD133 (NM_001145847), and $A C T B$ (NM_001101; see Table I). ACTB was used as a housekeeping gene control. Primers were synthesized by Eurofins Genomics. RNA isolation was performed using PureLink RNA Mini kit (Invitrogen, Thermo Fisher Scientific, Inc.) according to the manufacturer's protocol for mammalian cultured cells. RNA quantification was performed using NanoDrop (Thermo Fisher Scientific, Inc.). Complementary 
Table I. Primer sequences.

\section{Human}

\section{ACTB}

$\mathrm{F}$

$\mathrm{R}$

CTCGTCGCCCACATAGGAA

CD133

$\mathrm{F}$

$\mathrm{R}$

CAGATAAGTCAGCCAGGGAGC

Nestin

$\begin{array}{ll}\mathrm{F} & \text { GGTCCCTTCTGTGAACCAAC } \\ \mathrm{R} & \text { CAGATAAGTCAGCCAGGGAGC }\end{array}$

SOX2

$\mathrm{F}$

R

AAGCCCTGAAAGCGCAAGTCCTCAA GGCAGTGGTAGTGGTGGCATTAGCAG

\section{Mouse}

\begin{tabular}{ll} 
ACTB & \\
$\mathrm{F}$ & AAGAAGGCTATAGTCACCTCG \\
$\mathrm{R}$ & TGGTAATAATGCGGCCGGT \\
Nestin & \\
$\mathrm{F}$ & CTGGAAGAAGTTCCCAGGCTT \\
$\mathrm{R}$ & GAAGATGTGGAAGGAGAGCG \\
SOX2 & \\
$\mathrm{F}$ & ACAGCATGTCCTACTCGCAG \\
$\mathrm{R}$ & CCTCGGACTTGACCACAGAG \\
\hline
\end{tabular}

F, forward; R, reverse; SOX2, SRY (sex determining region Y)-box transcription factor 2 .

DNA (cDNA) was synthesized using qScript cDNA SuperMix (Quanta Biosciences) and Mastercycler nexus gradient (Eppendorf) according to manufacturers' protocols. Quantitative real-time PCR was performed using PerfeCTa SYBR Green FastMix (Quanta Biosciences) using Eco Real-Time PCR system (Illumina) according to manufacturers' protocols. The thermocycling conditions were as follows: Forty cycles of 2-step cycling were performed with denaturing at $95^{\circ} \mathrm{C}$ for $15 \mathrm{sec}$ and annealing at $60^{\circ} \mathrm{C}$ for $1 \mathrm{~min}$. Relative quantification was determined using the $2^{-\Delta \Delta \mathrm{Cq}}$ method (29).

Sphere formation assay. A sphere formation assay was used to qualitatively assess stemness. Dissociated single cells were seeded at either 10 or 100 cells per well in a 96-well plate with or without the addition of $1 \mu \mathrm{M}$ salinomycin $(\mathrm{n}=20)$. Cells were incubated at $37^{\circ} \mathrm{C}$ for 7 days and then were evaluated for sphere formation using light microscopy at a magnification of $\mathrm{x} 10$.

Limiting dilution assay. A limiting dilution assay was used as a functional assay for confirming stemness (2). Dissociated single cells were plated into 96 -well plates with various seeding densities (1-10 cells/well with 20 wells per condition) in NBE media with and without the addition of $1 \mu \mathrm{M}$ salinomycin $(n=8)$. Sphere formation was visually confirmed within each well. A diameter $>50 \mu \mathrm{m}$ was used as the criterion for counting spheres.

Statistical analysis. All experiments were performed with at least triplicates for each condition. Data were analyzed by a 2-tailed t-test with equal or unequal variance and ANOVA with Dunnett's multiple comparisons test. An f-test was used to determine variance prior to the t-test or ANOVA. Data with $\mathrm{P}<0.05$ were considered to indicate a statistically significant difference.

\section{Results}

As demonstrated in Fig. 1A, cells grown with serum adhered to the bottom of the flask and assumed an extended morphology. Alternatively, cells grown in serum-free culture remained suspended in the media and adhered to each other, forming spheres. Such a growth environment enriches the culture for GSCs. To validate this model, GSC markers SOX2, Nestin, and CD133 were analyzed by RT-qPCR. As revealed in Fig. 1B-D cells grown in serum-free culture had higher expression of these markers. For the U87 cell line, the difference in GSC marker expression was statistically significant for SOX2 and Nestin, but not for CD133. SMC448 exhibited statistical significance for all three GSC markers with $\mathrm{P}<0.01$ for both SOX2 and Nestin. D456 exhibited differences in GSC expression for all markers, albeit not at statistically significant levels.

Having established that serum-free culture enriched GSC-like cells, this culture method was used to assess the effectiveness of salinomycin against GSCs. Increasing doses of salinomycin were added to cells grown in both serum and serum-free culture. All three GBM cell lines exhibited a decreasing viability with increasing doses of salinomycin (Fig. 2). In both the U87 and SMC448 lines, the cells grown in serum-free culture had lower viabilities, suggesting the GSCs were more affected than the differentiated cancer cells in the serum culture. However, lower viabilities were observed in serum culture than in serum-free culture for the D456 cell line at all concentrations of salinomycin except at the highest $5 \mu \mathrm{M}$. This result was unexpected and may indicate the importance of the GBM subtype on the effectiveness of salinomycin. It could also be explained by the lack of a statistically significant difference in GSC markers between D456 cells grown in serum vs. serum-free culture. The non-cancerous neural stem cell line NE-4C was also investigated as a negative control (Fig. 2A). However, NE-4C cells exhibited significant toxicity to salinomycin in both serum and serum-free culture. This finding highlights the importance of understanding the mechanism of action of salinomycin and its effect on the GSC population.

To more thoroughly assess the effect of salinomycin on the GSC population, the mRNA expression of the GSC markers SOX2, Nestin, and CD133 was evaluated. Cells grown in sphere culture were treated for two days in triplicate with either $1 \mu \mathrm{M}$ salinomycin or $0.1 \%$ DMSO. Salinomycin treatment significantly decreased the $S O X 2$ expression in U87 and SMC448 cells and resulted in a non-statistically 
A

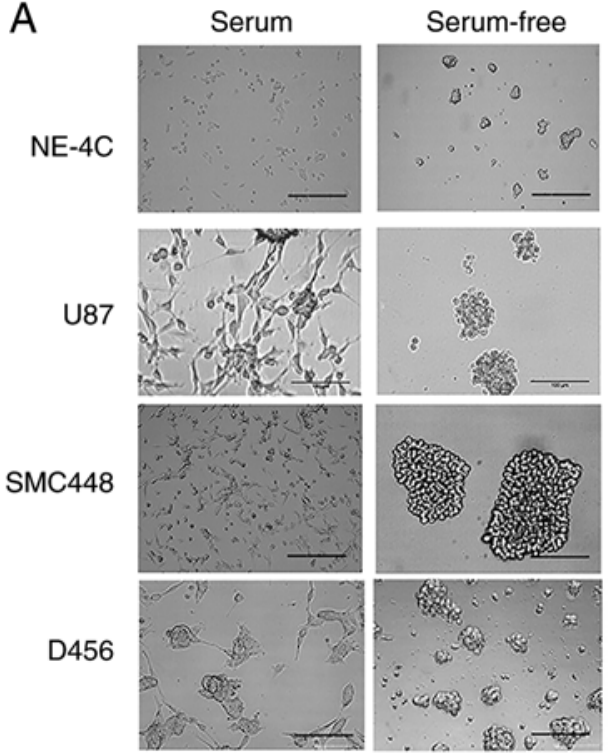

C

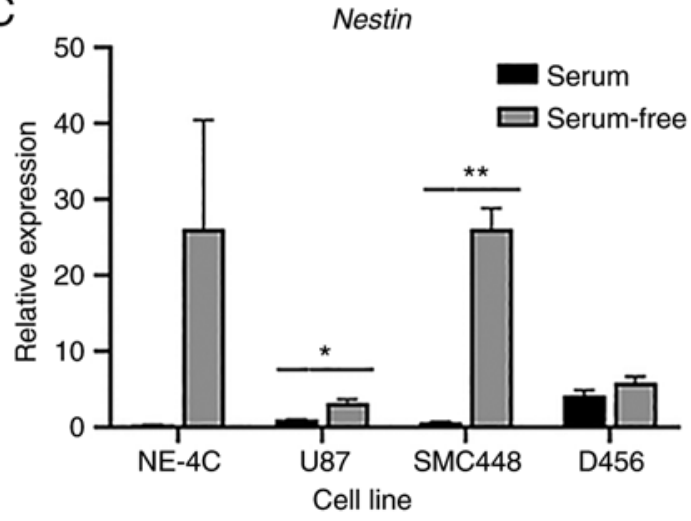

B

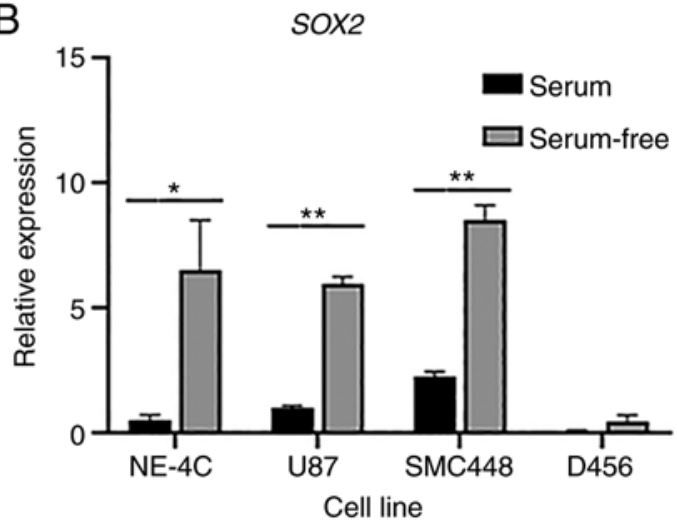

D

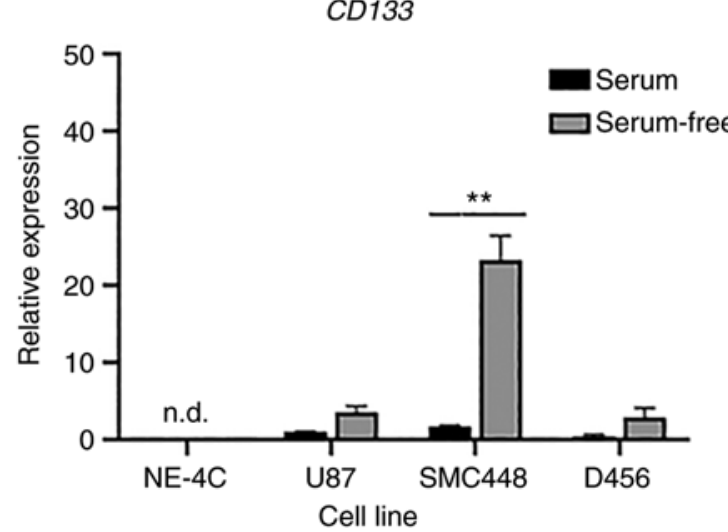

Figure 1. Serum-free culture enriches GSCs. GBM cells were grown in both serum and serum-free media and their expression of GSC markers were evaluated. (A) Representative bright-field images of NE-4C, U87, SMC448, and D456 cells after four days of growth in serum-free and serum-containing media exhibiting marked differences in cell morphology. Scale bar, $100 \mu \mathrm{m}$. (B-D) RT-qPCR analysis of the gene expression of (B) SOX2, (C) Nestin, and (D) CD133 for NE-4C, U87, SMC448, and D456 GBM cells. Error bars represent $95 \%$ confidence intervals $(\mathrm{n}=3)$. ${ }^{*} \mathrm{P}<0.05$, ${ }^{* *} \mathrm{P}<0.01$ for each gene compared to the serum culture counterpart. These results indicated increased stemness characteristics when GBM cells were grown in serum-free media. GSCs, glioblastoma stem cells; GBM, glioblastoma; SOX2, SRY (sex determining region Y)-box transcription factor 2.

significant decrease in SOX2 expression in D456 cells (Fig. 3A). However, the effect of salinomycin on Nestin and CD133 was inconsistent (Fig. 3B and C). Salinomycin increased the expression of Nestin in U87 cells, decreased its expression in SMC448 cells, and had no observable effect on its expression in D456 cells. None of these results were statistically significant. For CD133, salinomycin caused a statistically significant increase in U87 cells but minimal changes in SMC448 and D456. The variance in marker expression brings into question whether these markers are in fact assessing the same types of cells.

To further investigate the effect of salinomycin on GSCs, the protein expression and GSC functionality were assessed. Since salinomycin caused a decrease in $S O X 2$ mRNA expression for all three GBM cell lines, $S O X 2$ protein expression was analyzed using flow cytometry (Fig. 4). A statistically significant decrease in SOX2-positive population in D456 expression, with a similar decrease in U87 and SMC448 cells (albeit not at statistically significant levels) was revealed. Placed in context with the transcriptional results, these data indicated that while most of the cells continue to express SOX2, salinomycin is reducing the total amount of SOX2-positive population. The functional impact of salinomycin on GSC clonogenicity was assessed via sphere formation assay. Qualitatively, $1 \mu \mathrm{M}$ of salinomycin was sufficient to prevent sphere formation at both 10 and 100 cells/well seeding densities, even though these densities were otherwise sufficient to form spheres without salinomycin (Fig. 5A). Quantitatively using the extreme limiting dilution assay (30), a significant reduction of clonogenic population was also observed. Clonogenic potential of U87 cells was altered from 1 of 1.04 to 1 of 8.58 cells after 1 week of $1 \mu \mathrm{M}$ of salinomycin treatment (Fig. 5B). Similarly, the clonogenic potential of SMC448 was altered from 1 of 1.76 to 1 of 6.84 and D456 changed from 1 of 1.04 to 1 of 7.01 . Notably, the clonogenic potential of NE-4C mouse neural stem cells was also altered but to a lower extent from 1 of 1.15 to 1 of 4.63 (comparison of slopes of lines in Fig. 5B). Collectively, these data indicated that salinomycin significantly and selectively impacted GSC clonogenicity. 
A

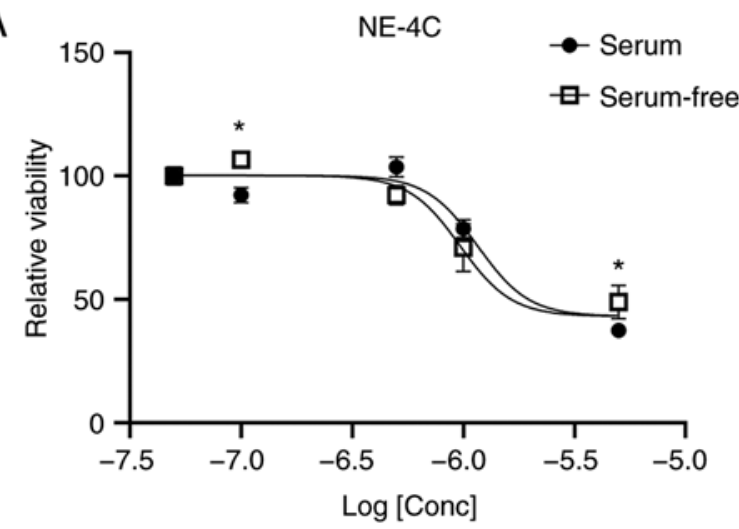

C

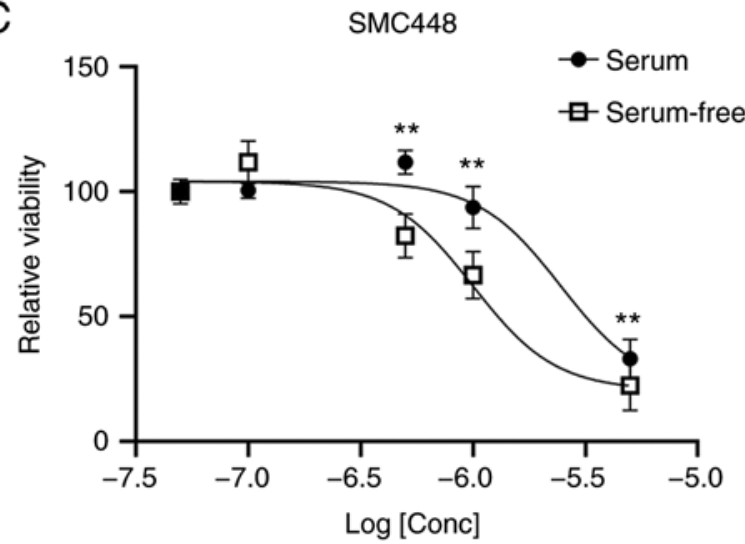

B
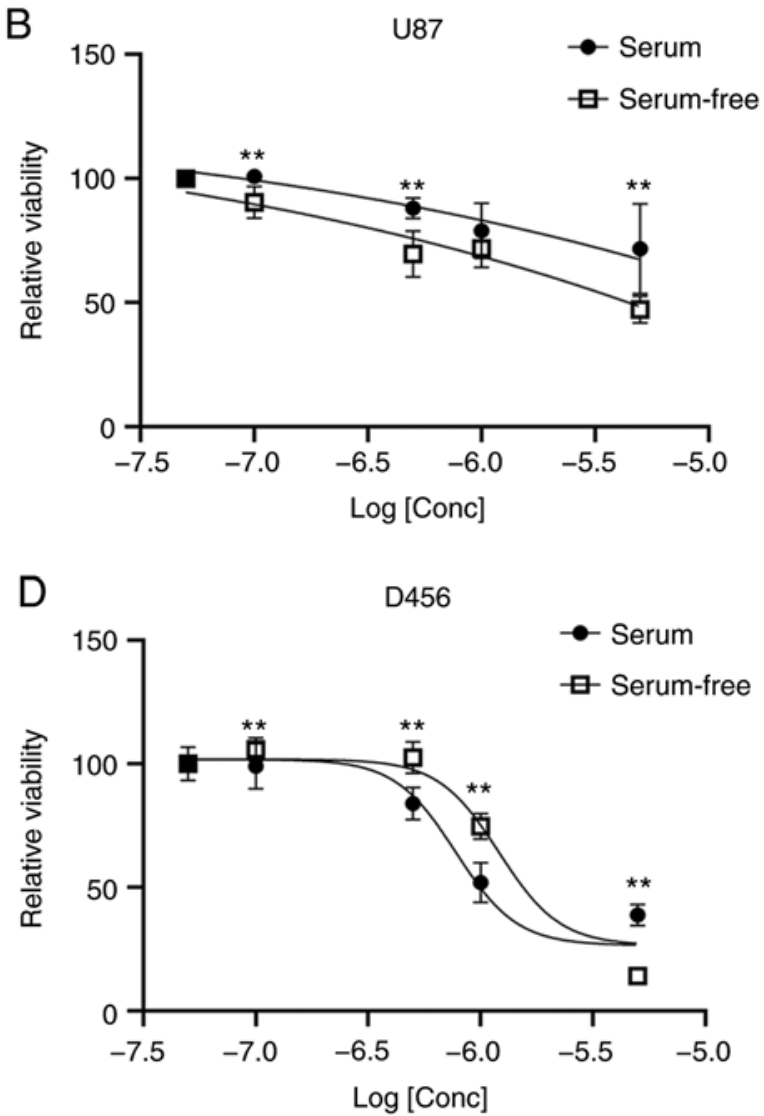

Figure 2. Salinomycin depletes populations of GBM cells. Cell viabilities of (A) NE-4C, (B) U87, (C) SMC448, and (D) D456 treated with varying concentrations of salinomycin were measured after $48 \mathrm{~h}\left(\mathrm{n}=8\right.$, mean $\pm 95 \%$ confidence intervals). ${ }^{*} \mathrm{P}<0.05$, ${ }^{* *} \mathrm{P}<0.01$ between serum and serum-free conditions. GBM, glioblastoma.
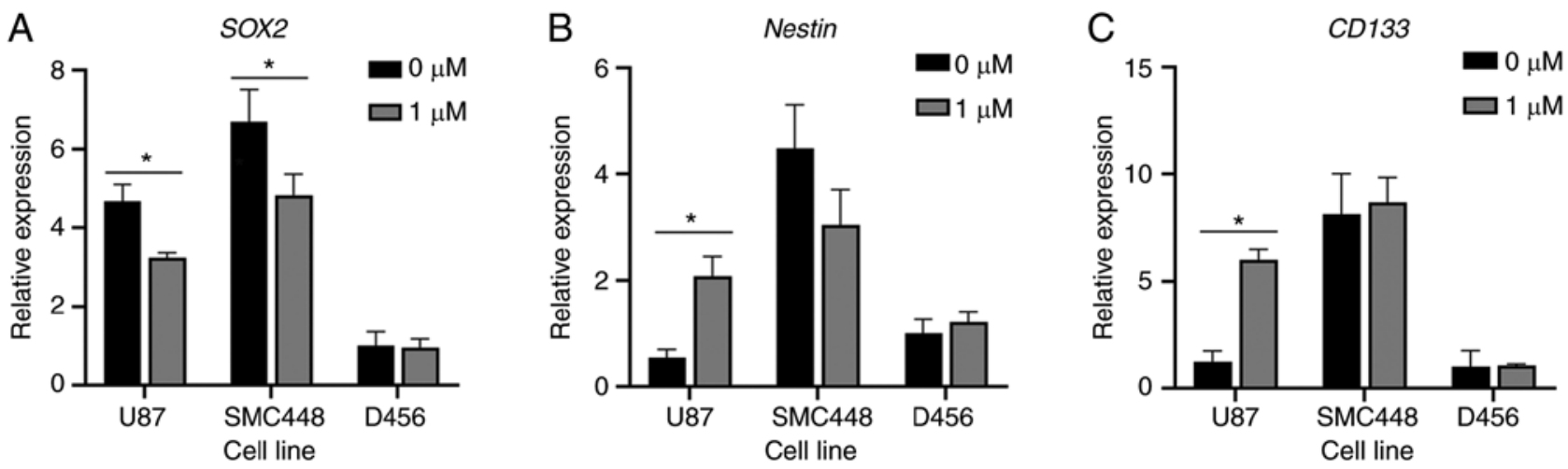

Figure 3. Effect of salinomycin on GSC marker mRNA expression. The ability of salinomycin ( $1 \mu \mathrm{M})$ or mock control $(0 \mu \mathrm{M})$ to decrease the expression of the GSC markers (A) SOX2, (B) Nestin, and (C) CD133 at the mRNA level after $48 \mathrm{~h}$ of treatment was determined using RT-qPCR. ACTB was used as the housekeeping gene. Expression levels were normalized to those of D456 control ( $\mathrm{n}=3$, mean $\pm 95 \%$ confidence intervals). $\mathrm{P}<0.05$. GSC, glioblastoma stem cell; SOX2, SRY (sex determining region Y)-box transcription factor 2.

To investigate the mechanism of action of salinomycin, an Annexin V/7-AAD assay was performed (Fig. 6A). This assay assesses the percentage of cells that are healthy (lower left quadrant), early apoptotic (lower right quadrant), late apoptotic (upper right quadrant), and necrotic (upper left quadrant). For all cell lines, salinomycin treatment led to an increased percentage of cells in the early apoptotic and late apoptotic quadrants, but no increase in the necrotic quadrant. This finding indicated that salinomycin induced cell death via apoptosis rather than necrosis. The cells grown in serum-free culture, which are GSC enriched, led to higher rates of specific apoptosis than those grown with serum, reinforcing the prior observation that salinomycin can to a certain extent preferentially deplete GSCs. For U87, the difference in the apoptotic rates between the serum-free culture and serum culture was statistically significant. The GBM lines U87, SMC448, and D456 all exhibited higher rates of specific apoptosis than the non-cancerous NE4C cell line, providing evidence that 
A
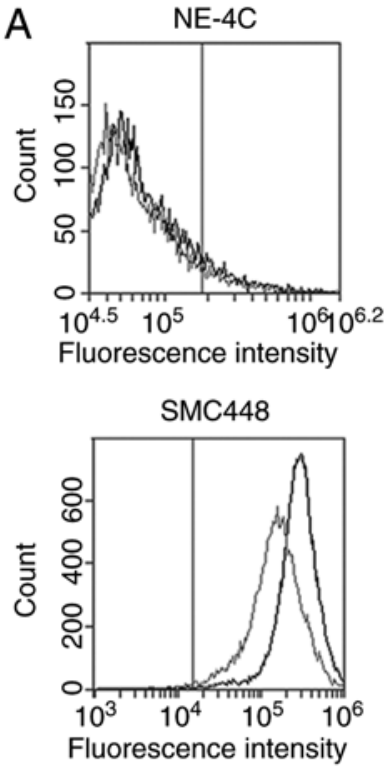

B

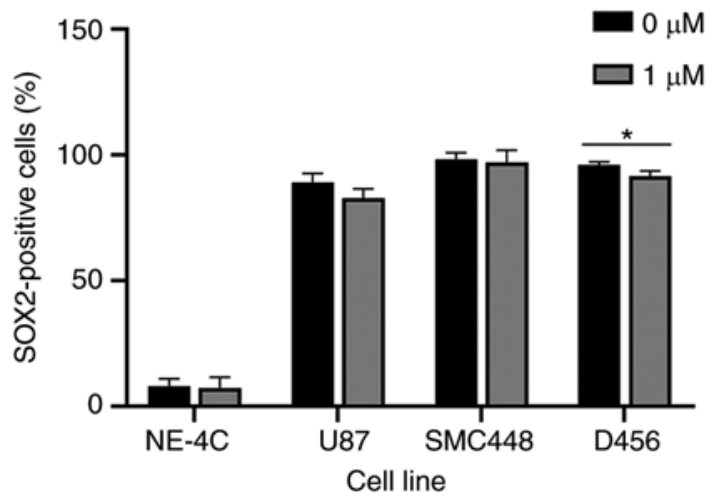

Figure 4. Effect of salinomycin on SOX2 protein expression. Percentage of NE-4C, U87, SMC448, and D456 serum-free cultured cells positive for SOX2 was analyzed via flow cytometry after $48 \mathrm{~h}$ of treatment with $1 \mu \mathrm{M}$ salinomycin (gray) or mock control (black). (A) Representative histograms for each cell line. Events to the right of the vertical line indicate SOX2-positive cells and (B) their quantification ( $\mathrm{n}=3$, mean $\pm 95 \%$ confidence intervals). ${ }^{*} \mathrm{P}<0.05$. SOX2, SRY (sex determining region Y)-box transcription factor 2.

salinomycin has greater toxicity for cancer cells than their non-cancerous counterparts. To further investigate this potential mechanism, flow cytometry was used to identify caspase-3 cleavage activity in serum-free and serum culture cells with or without the addition of salinomycin (Fig. 6B). Salinomycin treatment led to statistically significant increases in caspase-3 cleavage for SMC448 cells in serum culture as well as for both SMC448 and D456 cells in serum-free culture. The cells in serum and serum-free culture exhibited similar trends in caspase-3 cleavage, indicating that the increased apoptosis in U87 serum-free vs. serum culture may be caused by a caspase-3-indepdendent pathway $(31,32)$.

\section{Discussion}

We have previously postulated the potential of salinomycin to selectively target GSCs (20). While salinomycin is yet to be the subject of any full-scale clinical trials in cancer patients, its emergence as a key anticancer agent has propelled it into the focus of pre-clinical models using patient-derived cancer cells (33). The aim of the present study was to investigate the impact of salinomycin on GSC-like cells in GBM to assess the efficacy of the drug as a potential chemotherapy for GBM patients. GSCs are a distinct subpopulation of cells within glioblastomas which have the ability to initiate tumor growth and self-renew $(6,8,11)$. Conventional therapies do not adequately target these cell populations in glioblastoma, which may lead to inefficient tumor elimination and cancer reemergence $(11,34)$. The antibiotic salinomycin had been first identified to target CSCs nearly a decade ago, and subsequent studies on salinomycin have been centered on its potential to treat similar stem cell-like populations in various cancers (14). Additionally, drug delivery systems have been implemented in vitro with salinomycin to demonstrate the ability of the drug to deplete glioblastoma populations while also crossing the blood-brain barrier (35).

In the present study, the potential of salinomycin as a chemotherapeutic agent in the treatment of SOX2-positive GSCs was demonstrated. GSC populations within the tumor microenvironment must be targeted to adequately eliminate the tumor. One established human glioblastoma cell line (U87-MG) and two patient-derived glioblastoma cells lines (SMC448 and D456) were used in the present study. U87-MG is a well-established and widely used glioblastoma cell line of unknown origin that has been in culture since the 1960s (26). SMC448 is a radioresistant xenograft cell line derived from a high-grade glioma of unknown subtype (27). D456 is a glioblastoma of the proneural subtype that was derived from a human pediatric fronto-parietal GBM directly implanted into the flank of immunocompromised mice (28). Additionally, the mouse neural stem cell line NE-4C was used as a non-cancerous control. The present results revealed that salinomycin depleted the SOX2-positive GSC-enriched cell populations. Notably, the GSC markers Nestin and CD133 did not demonstrate the same consistent trend. This finding could indicate that SOX2, Nestin, and $C D 133$ are not measuring the same GSC population. This conclusion could be a result of a heterogenous GSC population or one or more of these markers not correctly identifying GSCs. An alternative conclusion could be that protein expression or conformation but not mRNA expression is indicative of the GSC population. Such a conclusion has been previously suggested for the detection of CD133 in colon cancer CSCs (36). Salinomycin was also demonstrated to decrease neurosphere formation and decrease the clonogenicity of GSC-like cells. Finally, it was demonstrated that salinomycin induced apoptotic cell death in GBM cells.

Salinomycin has previously been linked to apoptotic activity in leukemia, prostate, breast, and ovarian cancer $(16,17,37,38)$. There is great potential for targeting CSCs, including manipulating pro- and anti-apoptotic pathways in CSC populations (39). Salinomycin has additionally been demonstrated to overcome anti-apoptotic cellular mechanisms in human cancer cells (20). In the case of ovarian cancer specifically, it is known that the salinomycin-induced apoptotic pathway relies on the activation of caspase- 8 and death receptor 5 (40). Salinomycin has also been demonstrated to enhance the apoptotic activity of TRAIL in TRAIL-resistant GBM cells by modulating caspase-3 expression (41). The apoptotic effects of salinomycin have been shown to be retained even in biodegradable drug-delivery systems, an indication that this 
A

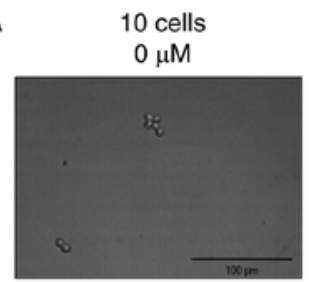

B

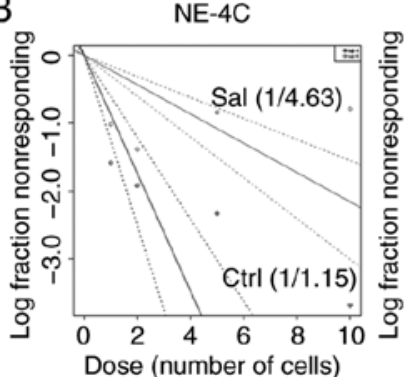

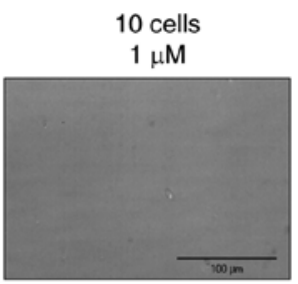

U87

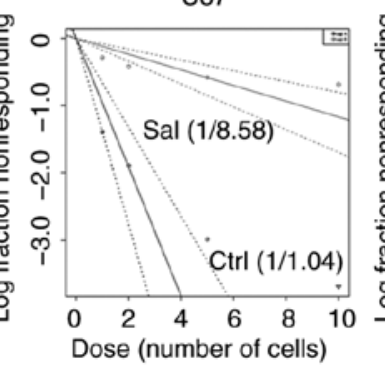

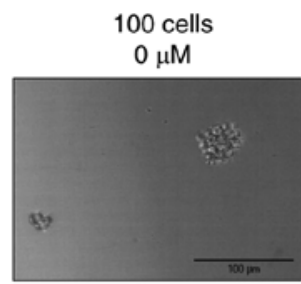

SMC448

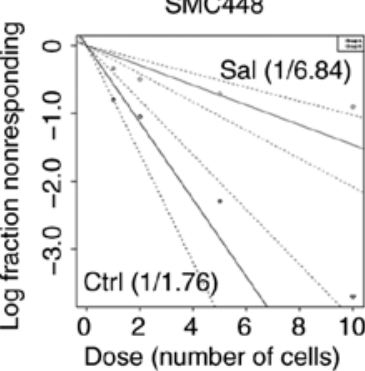

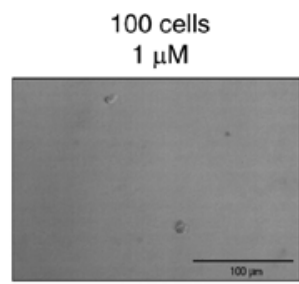

D456

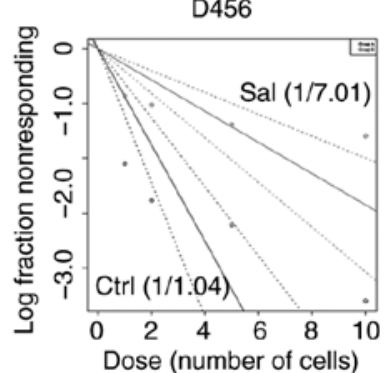

Figure 5. Salinomycin reduces clonogenicity. (A) Representative bright-field images of U87 cells seeded with either 10 or 100 cells/well and treated with either a mock control $(0 \mu \mathrm{M})$ or with $1 \mu \mathrm{M}$ salinomycin qualitatively revealing the loss of sphere formation after 1 week (scale bar, $50 \mu \mathrm{m})$. (B) Limiting dilution assay of NE-4C, U87, SMC448, and D456 was performed after 1 week of culture with $1 \mu \mathrm{M}$ salinomycin (Sal) and without (Ctrl). The steepness of the slope represents the frequency of clonogenic stem cells (dotted lines represent $95 \%$ confidence intervals). There was a significant reduction of clonogenic stem cells with salinomycin treatment $(\mathrm{P}<0.05)$.
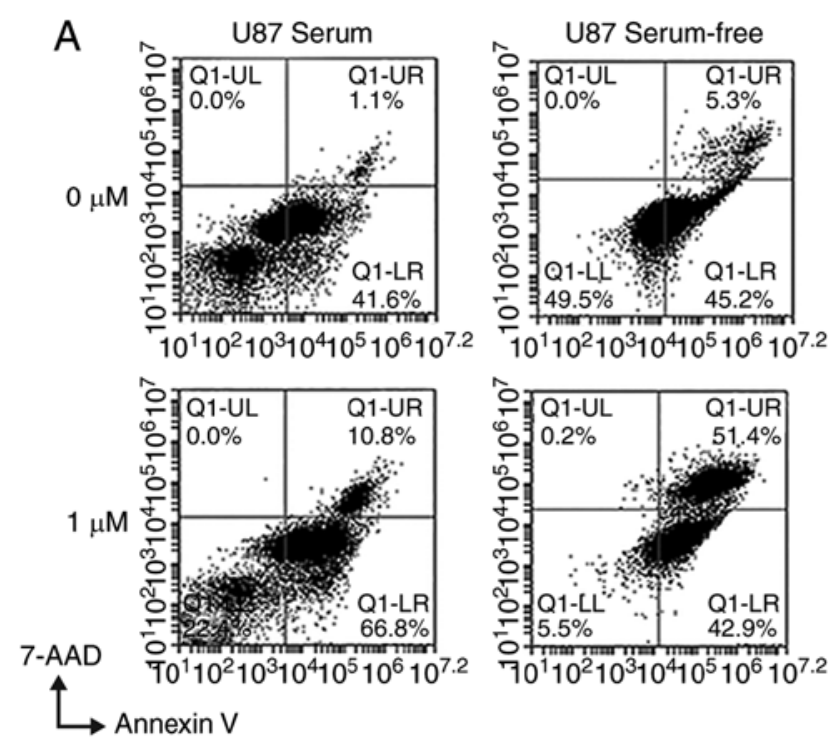

$\mathrm{B}$

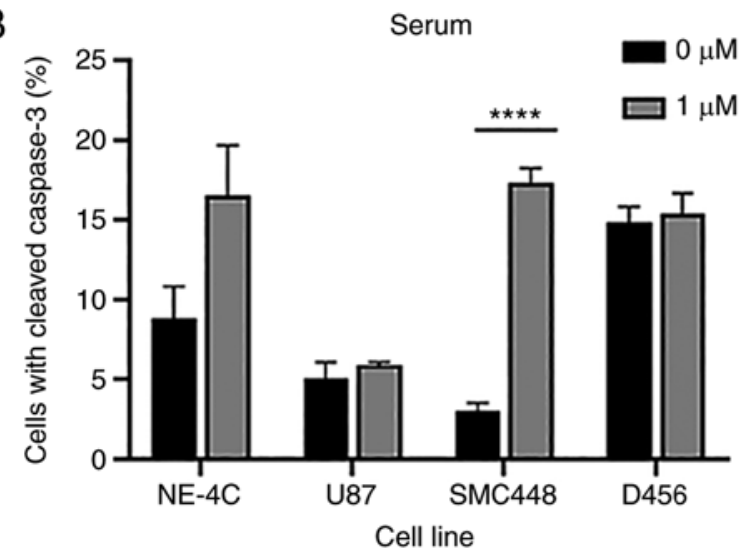

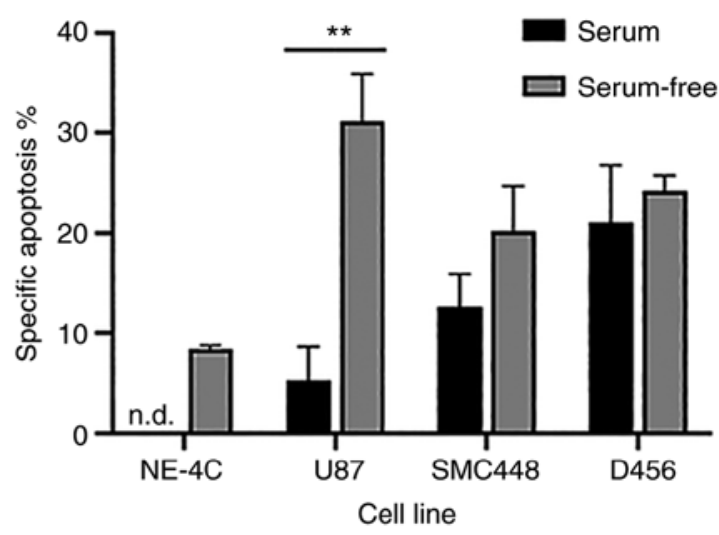

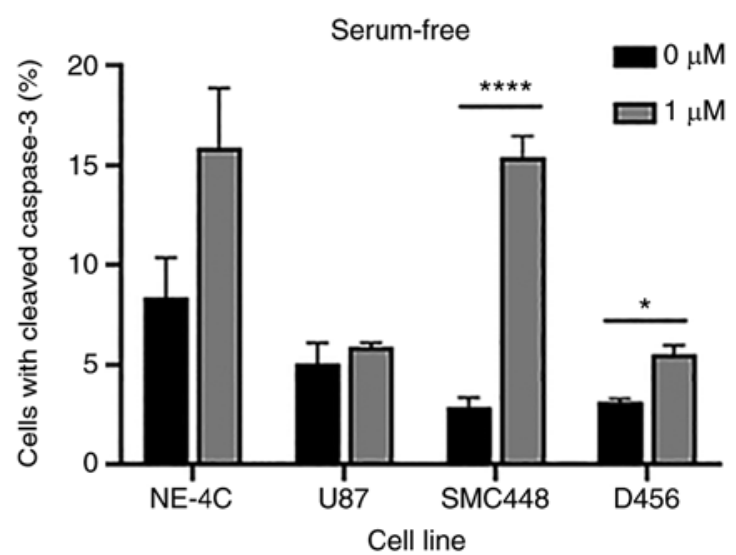

Figure 6. Salinomycin induces apoptosis in GBM. (A) Annexin V/7-AAD apoptosis assay was performed in NE-4C, U87, SMC448, and D456 serum and serum-free cultured cells. Representative flow cytometric plots of U87 cells with $(1 \mu \mathrm{M})$ and without $(0 \mu \mathrm{M}) 48 \mathrm{~h}$ treatment of salinomycin (left) and quantified specific apoptosis (right). The cells in serum-free culture (GSC-enriched) exhibited higher specific apoptosis than those grown in serum culture (differentiated cells) $\left(\mathrm{n}=3\right.$, mean $\pm 95 \%$ confidence intervals). ${ }^{* *} \mathrm{P}<0.01$. (B) Caspase-3 cleavage was determined for all cell lines cultured in serum (left) and serum-free (right) conditions ( $\mathrm{n}=3$, mean $\pm 95 \%$ confidence intervals). ${ }^{*} \mathrm{P}<0.05,{ }^{* * * * *} \mathrm{P}<0.0001$. GBM, glioblastoma; GSC, glioblastoma stem cell. 
pathway could serve as a point of interest in more advanced pre-clinical trials (42). Future study on salinomycin as a GBM treatment option should regard the apoptotic pathway as a factor that could help differentiate GSC death from normal neural cell death. Future studies should assess the effect of salinomycin on GBM in vivo to better understand its potential therapeutic benefits before translation to clinical testing.

In the development of new drugs to treat glioblastomas, it is important to consider the impact of these novel treatments on the function of normal brain tissue. Cases of neural toxicity induced by accidental salinomycin overdoses have been documented in humans and animals previously (43-45). Although our findings indicated that salinomycin decreased the sphere formation potential for the non-cancerous stem cell line NE-4C, they also revealed that salinomycin toxicity took effect at a higher concentration for this neural stem cell line than the GBM cell lines assessed. Additionally, the shifts in apoptotic activity induced by salinomycin were not significant for NE-4C where large shifts were observed in the glioblastoma lines. It has also been observed that salinomycin triggers calcium-induced apoptosis in Schwann cells and dorsal root ganglia, but this effect can be inhibited by $\mathrm{Na}^{+} / \mathrm{Ca}^{+}$exchanger inhibitors (46). A potential avenue that may prove useful for subsequent salinomycin studies is the implementation of synthetic structural analogs of the drug that exhibit lower levels of toxicity towards healthy cells (47). Salinomycin has also been demonstrated to have synergistic DNA damage effects when combined with the common chemotherapy drug temozolomide, highlighting the potential of salinomycin in combination therapies (48). As the drug is researched more thoroughly within glioblastoma studies and other cancers, our findings reaffirm that salinomycin toxicity towards healthy cells must be a contributing factor towards the implementation of the ionophore as a chemotherapeutic agent.

\section{Acknowledgements}

We gratefully acknowledge Dr Do-Hyun Nam (Samsung Medical Center,Seoul, South Korea) and Dr G. Yancey Gillespie (University of Alabama at Birmingham, Birmingham, AL) for kindly providing SMC448 and D456 patient-derived GBM lines, respectively.

\section{Funding}

The present study was supported by the National Science Foundation under grant no. 1604677 (to YK), by The University of Alabama Office for Research and Economic Development (to YK), and by The University of Alabama Randall Research Scholars Program (to JWM and WRR).

\section{Availability of data and materials}

All data generated or analyzed during this study are included in this published article.

\section{Authors' contributions}

JWM and YK conceived and designed the study. JWM and WRR conducted the experiments and acquired the data.
JWM, WRR and YK were involved in the experimental design, data analysis, interpretation of data, and drafted and revised the manuscript. All authors read the final manuscript and agree to be accountable for all aspects of the work in ensuring that questions related to the accuracy or integrity of any part of the work are appropriately investigated and resolved.

\section{Ethics approval and consent to participate}

Not applicable.

\section{Patient consent for publication}

Not applicable.

\section{Competing interests}

The authors declare that they have no competing interests.

\section{References}

1. Arvold ND and Reardon DA: Treatment options and outcomes for glioblastoma in the elderly patient. Clin Interv Aging 9: 357-367, 2014.

2. Hanif F, Muzaffar K, Perveen K, Malhi SM and Simjee ShU: Glioblastoma multiforme: A review of its epidemiology and pathogenesis through clinical presentation and treatment. Asian Pac J Cancer Prev 18: 3-9, 2017.

3. Tamimi AF and Juweid M: Epidemiology and outcome of glioblastoma. Chapter 8. In: Glioblastoma [Internet]. De Vleeschouwer S (ed). Codon Publications, Brisbane (AU), $29251870,2017$.

4. Stupp R, Mason WP, van den Bent MJ, Weller M, Fisher B, Taphoorn MJ, Belanger K, Brandes AA, Marosi C, Bogdahn U, et al: Radiotherapy plus concomitant and adjuvant temozolomide for glioblastoma. N Engl J Med 352: 987-996, 2005.

5. Bonnet D and Dick JE: Human acute myeloid leukemia is organized as a hierarchy that originates from a primitive hematopoietic cell. Nat Med 3: 730-737, 1997.

6. Singh SK, Hawkins C, Clarke ID, Squire JA, Bayani J, Hide T, Henkelman RM, Cusimano MD and Dirks PB: Identification of human brain tumour initiating cells. Nature 432: 396-401, 2004.

7. Galli R, Binda E, Orfanelli U, Cipelletti B, Gritti A, De Vitis S, Fiocco R, Foroni C, Dimeco F and Vescovi A: Isolation and characterization of tumorigenic, stem-like neural precursors from human glioblastoma. Cancer Res 64: 7011-7021, 2004.

8. Singh SK, Clarke ID, Terasaki M, Bonn VE, Hawkins C, Squire J and Dirks PB: Identification of a cancer stem cell in human brain tumors. Cancer Res 63: 5821-5828, 2003.

9. Bao S, Wu Q, McLendon RE, Hao Y, Shi Q, Hjelmeland AB, Dewhirst MW, Bigner DD and Rich JN: Glioma stem cells promote radioresistance by preferential activation of the DNA damage response. Nature 444: 756-760, 2006.

10. Kim Y, Joo KM, Jin J and Nam DH: Cancer stem cells and their mechanism of chemo-radiation resistance. Int J Stem Cells 2: 109-114, 2009

11. Lathia JD, Mack SC, Mulkearns-Hubert EE, Valentim CL and Rich JN: Cancer stem cells in glioblastoma. Genes Dev 29: 1203-1217, 2015.

12. Song WS, Yang YP, Huang CS, Lu KH, Liu WH, Wu WW, Lee YY, Lo WL, Lee SD, Chen YW, et al: Sox2, a stemness gene, regulates tumor-initiating and drug-resistant properties in CD133-positive glioblastoma stem cells. J Chin Med Assoc 79: 538-545, 2016.

13. Neradil $\mathbf{J}$ and Veselska R: Nestin as a marker of cancer stem cells. Cancer Sci 106: 803-811, 2015.

14. Gupta PB, Onder TT, Jiang G, Tao K, Kuperwasser C, Weinberg RA and Lander ES: Identification of selective inhibitors of cancer stem cells by high-throughput screening. Cell 138: 645-659, 2009. 
15. Mitani M, Yamanishi T and Miyazaki Y: Salinomycin: A new monovalent cation ionophore. Biochem Biophys Res Commun 66: 1231-1236, 1975.

16. Dong TT, Zhou HM, Wang LL, Feng B, Lv B and Zheng MH: Salinomycin selectively targets ' $\mathrm{CD} 133^{+}$' cell subpopulations and decreases malignant traits in colorectal cancer lines. Ann Surg Oncol 18: 1797-1804, 2011.

17. Wang Y: Effects of salinomycin on cancer stem cell in human lung adenocarcinoma A549 cells. Med Chem 7: 106-111, 2011.

18. Kim KY, Yu SN, Lee SY, Chun SS, Choi YL, Park YM, Song CS, Chatterjee B and Ahn SC: Salinomycin-induced apoptosis of human prostate cancer cells due to accumulated reactive oxygen species and mitochondrial membrane depolarization. Biochem Biophys Res Commun 413: 80-86, 2011

19. Fuchs D, Daniel V, Sadeghi M, Opelz G and Naujokat C: Salinomycin overcomes ABC transporter-mediated multidrug and apoptosis resistance in human leukemia stem cell-like KG-1a cells. Biochem Biophys Res Commun 394: 1098-1104, 2010.

20. Fuchs D, Heinold A, Opelz G, Daniel V and Naujokat C: Salinomycin induces apoptosis and overcomes apoptosis resistance in human cancer cells. Biochem Biophys Res Commun 390 743-749, 2009

21. Lu D, Choi MY, Yu J, Castro JE, Kipps TJ and Carson DA: Salinomycin inhibits Wnt signaling and selectively induces apoptosis in chronic lymphocytic leukemia cells. Proc Natl Acad Sci USA 108: 13253-13257, 2011.

22. Magrath JW and Kim Y: Salinomycin's potential to eliminate glioblastoma stem cells and treat glioblastoma multiforme (Review). Int J Oncol 51: 753-759, 2017.

23. Chen T, Yi L, Li F, Hu R, Hu S, Yin Y, Lan C, Li Z, Fu C, Cao L, et al: Salinomycin inhibits the tumor growth of glioma stem cells by selectively suppressing glioma-initiating cells. Mol Med Rep 11: 2407-2412, 2015

24. Qin LS, Jia PF,Zhang ZQ and Zhang SM: ROS-p53-cyclophilin-D signaling mediates salinomycin-induced glioma cell necrosis J Exp Clin Cancer Res 34: 57, 2015.

25. Xipell E, Gonzalez-Huarriz M, Martinez de Irujo JJ, García-Garzón A, Lang FF, Jiang H, Fueyo J, Gomez-Manzano C and Alonso MM: Salinomycin induced ROS results in abortive autophagy and leads to regulated necrosis in glioblastoma. Oncotarget 7: 30626-30641, 2016

26. Allen M, Bjerke M, Edlund H, Nelander S and Westermark B Origin of the U87MG glioma cell line: Good news and bad news. Sci Transl Med 8: 354re3, 2016.

27. Joo KM, Kim J, Jin J, Kim M, Seol HJ, Muradov J, Yang H, Choi YL, Park WY, Kong DS, et al: Patient-specific orthotopic glioblastoma xenograft models recapitulate the histopathology and biology of human glioblastomas in situ. Cell Rep 3: 260-273 2013.

28. Friedman GK, Langford CP, Coleman JM, Cassady KA, Parker JN, Markert JM and Yancey Gillespie G: Engineered herpes simplex viruses efficiently infect and kill $\mathrm{CD} 133^{+}$human glioma xenograft cells that express CD111. J Neurooncol 95 199-209, 2009

29. Livak KJ and Schmittgen TD: Analysis of relative gene expression data using real-time quantitative PCR and the 2(-Delta Delta C(T)) method. Methods 25: 402-408, 2001.

30. Hu Y and Smyth GK: ELDA: Extreme limiting dilution analysis for comparing depleted and enriched populations in stem cell and other assays. J Immunol Methods 347: 70-78, 2009.

31. Bai X, Kinney WH, Su WL, Bai A, Ovrutsky AR, Honda JR, Netea MG, Henao-Tamayo M, Ordway DJ, Dinarello CA and Chan ED: Caspase-3-independent apoptotic pathways contribute to interleukin-32 $\gamma$-mediated control of mycobacterium tuberculosis infection in THP-1 cells. BMC Microbiol 15: 39, 2015
32. Liu G, Zou H, Luo T, Long M, Bian J, Liu X, Gu J, Yuan Y, Song R, Wang Y, et al: Caspase-dependent and caspase-independent pathways are involved in cadmium-induced apoptosis in primary rat proximal tubular cell culture. PLoS One 11: $\mathrm{e} 0166823,2016$.

33. Klose J, Trefz S, Wagner T, Steffen L, Preißendörfer Charrier A, Radhakrishnan P, Volz C, Schmidt T, Ulrich A, Dieter SM, et al: Salinomycin: Anti-tumor activity in a pre-clinical colorectal cancer model. PLoS One 14: e0211916, 2019.

34. Reya T, Morrison SJ, Clarke MF and Weissman IL: Stem cells, cancer, and cancer stem cells. Nature 414: 105-111, 2001.

35. Tigli Aydin RS, Kaynak G and Gumusderelioglu M: Salinomycin encapsulated nanoparticles as a targeting vehicle for glioblastoma cells. J Biomed Mater Res A 104: 455-464, 2016.

36. Kemper K, Sprick MR, de Bree M, Scopelliti A, Vermeulen L, Hoek M, Zeilstra J, Pals ST, Mehmet H, Stassi G and Medema JP: The AC133 epitope, but not the CD133 protein, is lost upon cancer stem cell differentiation. Cancer Res 70: 719-729, 2010.

37. Al Dhaheri Y, Attoub S, Arafat K, Abuqamar S, Eid A, Al Faresi N and Iratni R: Salinomycin induces apoptosis and senescence in breast cancer: Upregulation of p21, downregulation of survivin and histone $\mathrm{H} 3$ and $\mathrm{H} 4$ hyperacetylation. Biochim Biophys Acta 1830: 3121-3135, 2013.

38. Kaplan F and Teksen F: Apoptotic effects of salinomycin on human ovarian cancer cell line (OVCAR-3). Tumour Biol 37: 3897-3903, 2016

39. He YC, Zhou FL, Shen Y, Liao DF and Cao D: Apoptotic death of cancer stem cells for cancer therapy. Int J Mol Sci 15: 8335-8351, 2014.

40. Parajuli B, Shin SJ, Kwon SH, Cha SD, Chung R, Park WJ, Lee $\mathrm{HG}$ and Cho $\mathrm{CH}$ : Salinomycin induces apoptosis via death receptor-5 up-regulation in cisplatin-resistant ovarian cancer cells. Anticancer Res 33: 1457-1462, 2013.

41. Calzolari A, Saulle E, De Angelis ML, Pasquini L, Boe A, Pelacchi F, Ricci-Vitiani L, Baiocchi M and Testa U: Salinomycin potentiates the cytotoxic effects of TRAIL on glioblastoma cell lines. PLoS One 9: e94438, 2014.

42. Norouzi M, Abdali Z, Liu S and Miller DW: Salinomycin-loaded nanofibers for glioblastoma therapy. Sci Rep 8: 9377, 2018.

43. Rollinson J, Taylor FG and Chesney J: Salinomycin poisoning in horses. Vet Rec 121: 126-128, 1987.

44. Story $P$ and Doube A: A case of human poisoning by salinomycin, an agricultural antibiotic. N Z Med J 117: U799, 2004.

45. van der Linde-Sipman JS, van den Ingh TS, van nes JJ, Verhagen $H$, Kersten JG, Beynen AC and Plekkringa R: Salinomycin-induced polyneuropathy in cats: Morphologic and epidemiologic data. Vet Pathol 36: 152-156, 1999.

46. Boehmerle W and Endres M: Salinomycin induces calpain and cytochrome C-mediated neuronal cell death. Cell Death Dis 2: e168, 2011.

47. Borgstrom B, Huang X, Hegardt C, Oredsson S and Strand D: Structure-activity relationships in salinomycin: Cytotoxicity and phenotype selectivity of semi-synthetic derivatives. Chemistry 23: 2077-2083, 2017.

48. Xipell E, Aragón T, Martinez-Velez N, Vera B, Idoate MA, Martínez-Irujo JJ, Garzón AG, Gonzalez-Huarriz M, Acanda AM, Jones C, et al: Endoplasmic reticulum stress-inducing drugs sensitize glioma cells to temozolomide through downregulation of MGMT, MPG, and Rad51. Neuro Oncol 18: 1109-1119, 2016. 